\title{
Development of Production Rates Database for Substructure Activities by Work Sampling
}

\author{
Arazi Idrus \\ Department of Civil Engineering, Universiti Teknologi Petronas \\ PO box 31750, Tronoh, Malaysia \\ Tel: 60-12-207-325 E-mail: arazi_idrus@petronas.com.my \\ Sana Muqeem \\ Department of Civil Engineering, Universiti Teknologi Petronas \\ PO box 31750, Tronoh, Malaysia \\ Tel: 60-17-557-9811Ｅ-mail: sanamuqeem@yahoo.com \\ Saiful Bin Zakaria \\ Department of Civil Engineering, Universiti Teknologi Petronas \\ PO box 31750, Tronoh, Malaysia \\ Tel: 60-19-599-5492Ｅ-mail: saifulsshi_sa@yahoo.com.my \\ Muhamad Nazim bin Mohamad Nawi \\ Department of Civil Engineering, Universiti Teknologi Petronas \\ PO box 31750, Tronoh, Malaysia \\ Tel: 60-12-909-4950Ｅ-mail: enzim04@gmail.com
}

Received: April 5, 2011

Accepted: May 2, 2011

doi:10.5539/mas.v5n4p123

\begin{abstract}
For successful completion of a construction project, scheduling of construction activities on site is very important. Production rate is one of the important data needed for determining activity duration and hence for scheduling of the activities in a project. However, because production rates are greatly affected by various controlled and uncontrolled factors, no specific calculations can be derived to produce them. Because of this, their values have all been based on experience and judgment of the individual construction manager, as well as from previous company records. The aim of this research is to develop an initial database of "moderated" production rates for selected activities of sub structural works, which can be made accessible to everyone in the industry. Work sampling approach has been used in this research to elicit data on production rates on site using stopwatch and video recording technique. Data collected were compiled and analyzed using descriptive statistics. It was found that the research had produced an acceptably reliable production rate values for each activity.
\end{abstract}

Keywords: Production rates, Database, Statistical analysis, Direct observation

\section{Introduction}

In construction, information on activity duration is essential in scheduling the construction activities on site, particularly in costing the activities in predicting overall project completion time. There is therefore a need to elicit and compile such information and subsequently analyzed to develop an initial database of moderated production rates, which can be made accessible by everyone in the industry. Production rate (productivity rate in this research is defined as "the number of units of production that can be generated over some unit of time" (Halpin and Woodhead 1998).

According to the literature, most of the research done on production rates of construction works have focused on collection on data by questionnaire survey such as research studies conducted in Malaysia for developing a production rates database of civil and structural works by questionnaire survey, based on questionnaire surveys another research conducted for developing production rates database for external construction works, similarly study has been done for developing production rate database for precast construction works for IBS systems (Kamaluddin et al. 2006), (Sana et al. 2010), (Arazi et al. 2010). More recently there is an ongoing research looking into the possibility of producing production rates by neuro-fuzzy computational modeling (Sana et al. 2011).

However, in Malaysia there is not much research on collecting production rates data by work sampling on site there is no such research done by using this approach for collecting data from construction site is reported in literature except for the one on Industrialized Building System on precast construction works (Arazi et al. 2011). 
Research on work sampling of production rates data of substructure works of a building project is still lacking. Therefore, objective of this research is to develop a database for sub structure activities by work sampling. To achieve this objective, the following tasks are required to be done: 1) Data collection of production rates of some selected activities of substructure works by identifying the building projects. 2) Data compilation and analysis of the production rates through statistical analysis. 3) Development of database of production rates of substructure works.

\section{Methodology}

In order to achieve the objective of the research the methodology adopted is as follows:

\subsection{Data Collection}

Researchers have identified that the method of data collection used influenced the accuracy of the production rates values. Questionnaire survey is the most commonly used method of data collection usually adopted by the researchers to collect information on factors and production rates in a cost effective way but the reliability and accuracy of the results cannot be proved.

In order to get more accurate value of production rates, work sampling approach has been developed in which rates are measure directly in the field. Work sampling is the technique used for data collection that observes the labor activities at fixed predetermined intervals (Oglesby et al. 1989). It has been identified as the most relevant and authentic method for measuring and evaluating productivity performance on site. It provides précised, detailed and real time information on production rates (Sweis 2000), (Liou and Borcherding 1986). Therefore, work sampling approach has been adopted for measuring production rates for substructure construction works in this research. Before going to the field, a standard data collection forms has been constructed to record the data. Form contains the production rate, the number and type of machineries used, number of labors. During the field observations, the time taken to complete each activity is recorded and work done is measured to obtain the production rate.

Before initiating data collection process, the pilot survey is done to finalize the activities that are reliable to for measuring the production rate from different projects as different projects used different type of piling method substructure activities that will lead to different cycle of activities that need to be observed and measured differently. Also the observant at the site was present at least for a complete cycle of main sub-activity of substructure activities otherwise without proper planning; the observant may miss the critical substructure activity. The standard construction guidelines depend on the area of the construction. For example, all projects in the area of Dewan Bandaraya Kuala Lumpur (DBKL) need to use bore pile as the piling method.

There are four (4) projects selected to be observed by using work sampling method. Among the four projects, three (3) of them are education buildings and one is commercial building. However, all of the projects are constructed by government body; Jabatan Kerja Raya (JKR) at respective states, and the private contractor had been appointed by JKR as the constructer of their project. Every appointed contractor must follow all the standards that had been set by JKR under Sistem Pengurusan Kualiti (SPK-JKR) of implementing MS ISO 9001-2000. The production rates of activities were not very much different at different sites as the same standard has been followed.There are twenty four (24) sets of data obtained from direct observation for selected substructure activities. Piling activity has been divided based on its respective piling type. It is because the activities involved in each type of piling are not same. They need to be put in their own group of activities. There are eighteen (18) sets of data measured for piling spun pile and six (6) sets of production rates for piling micro pile.

\subsection{Data Analysis}

Data collected has been analyzed by using statistical analysis. Mean and Variance of production rate values of each activity have been calculated. Then, Analysis of Variance (ANOVA) has been calculated for each activity to determine the variation of the mean among the sets of data collected from four different projects.

\subsection{Database Development}

After statistical analysis, the database for final production rates for each substructure activities has been compiled. Database developed in this research can be made accessible to be used by everyone in the industry.

\section{Results and Discussion}

Mean and variance for each activity have been calculated for the raw data of production rates values measured. The statistical analysis for raw data is shown below in the Table 1. The variance calculated for spun pile type of pile driven activity was very high. Even though it has been categorized into its respective type of pile, but the value is still high. To strengthen the values, Analysis of Variance (ANOVA) has been calculated for each activity to determine the variation of the mean among the sets of data collected from four different projects as shown in Figure 1. ANOVA has been calculated in order to verify that the sets of data collected from four projects are normally distributed, have equal variance and mutually independent from each other. The results of P-values obtained by calculating ANOVA for each activity have analyzed. As the P-value $<0.05$ indicates that there is significant difference between mean of different sets of data with high variance. The P-value calculated for Spun pile and Micro pile is $3.15 \mathrm{e}-05$ which is very small which represents high variation among the sets of data 
collected from four projects. The reason contribute to the high variance value is because the type of the soil at three (3) respective sites is different. Actually, the site at Kelantan has been built on fine grained soil whereas the site in Ipoh is piled on coarse grained soil. When piling is done on fine grained soil, the production rate is much higher compare to coarse grained soil because fine grained soil has longer consolidation time. By classifying into type of soil, the value of variance obtained is lower and the mean can be taken as final production rates value.

For excavation activity Table 1 shows a large value of variance which is 128.78 . Similarly, the P-value calculated for excavation activity is equal to $2.08 \mathrm{e}-008$ which is very smaller as compare to the other activities as shown in Figure 1. Thus, indicating that production rate values measured for excavation are significantly varied from one project to other project. The reason of such variance is because different contractor use different bucket size of machinery (backhoe). Thus, the mean cannot be accepted as the measure of central tendency for that activity. Therefore, the production rate of the activity cannot be taken as mean value.

However, the activities such as formwork, reinforcement and stump have very low variation as represented by their P-values shown in Figure 1. Therefore, except the two activities that have large value of variance, all activities show a lower value of variance. This indicates that, the mean value for those activities can be taken as the final production rates. There are two factors contribute to the low variance values which includes real time data collected through work sampling and the second one is, the implementation of SPK-JKR quality standard under MS ISO 9001 that had been introduced by JKR.

In short, it is proved that work sampling approach is real time and the most appropriate method used to predict the productivity as compared to other method of data collection data such as questionnaire survey. Thus, work sampling approach has been proven to act as a good indicator of productivity.

During data collection at different sites, it was realized that a lot of factors affected the progress of this research. Firstly, external hindrances came from getting approvals to enter sites, secondly, project sites were not accessible as they were located in different states and the lastly coordination with the contractor during data collection. Also, internal challenge came from the nature of conducting direct observation itself, especially for observing substructure activities. It took a lot of time to finish each cycle of substructure activities. Comparing to observing superstructure activity, the challenge is different because substructure activities is once-time-cycle. If the observation for certain activity has been finished, no repetition was there for that activity anymore. Another factor affecting production rate is number of gang size at site. To ensure the reliability of suggested database of production rates, the type of gang size with regard to its number of workers range also shown in the Table 2 . During observation, even though executing the same activity, there were different numbers of worker at different sites. But the difference is not more than one (1) worker whether it is less or more.

The numbers of worker have been classified into 4 types of gang size. Type A for 1-2 workers of gang size, type B for 3-4 workers, type C for 5-6 workers, and type D for 7-8 workers. Hence, the final production rates presented are the outcome of data collected during direct observation is with respect to the type of gang size. The types of gang size with regard to each activity of substructure activities are shown in the Table 2 . Besides, there are also a few other factors that may affect production rates which are machinery capacity and site supervision.

Ultimately, the database for final production rates for each substructure activities is compiled and presented in Table 3. The production rates are precise enough to be accepted as a database for project estimation.

\section{Conclusion}

The objective of the research has been achieved successfully and the tasks that were required to be done have been completed as follows: 1) Work sampling approach has been used in collecting data for production rates from four projects. The data collected by work sampling is most reliable because it is based on real time result, sufficiently added with photos and videos to interpret contextual information for analysis, 2) Data has been statistically analyzed and moderated by calculating ANOVA, mean and variance. The analysis indicates that production rates values have low value of variance. 3) Production rates have been compiled after moderation for the development of initial database of substructure activity.

Hence, production rates database developed by using work sampling approach can be reliably used in future and helps in improving the productivity of construction projects. It is useful as a reference to academia and also can be used in industry. Albeit basing on only 4 projects, the research conducted is an initial step towards the development of a precise database of production rates and can be considered as a contribution to the existing knowledge.

\section{Recommendation}

For optimal implementation of this research, there is room for improvement to be made. First, the frequency of direct observation can be increased so that the data obtained will be larger. Therefore, the outcome of statistical analysis will lead to an accurate database of production rate.

Also future research should include the measurement of the factors affecting production rates at site in order to get more accurate and reliable values of production rates.

Besides, there is a need to widen the scope of direct observation by collecting data for high rise building in future, so that the variability of the data can be compared with this research. 


\section{References}

Arazi Idrus, Sana Muqeem, Mohd Saiful Zakaria, Wira Azizi. (2011). Development of Production Rates Database System for IBS Components in Malaysian Construction Industry. Canadian Journal; Journal of Environmental, Construction Civil Engineering, Vol. 2, No.1, Januray 2011.

Arazi Idrus, Sana Muqeem, Mohd Saiful Zakarai and Zairul Aziyah. (2010). Development of Production Rates Database for Precast Concrete Construction works. International Conference on Construction and Project Management. Chengdu, China 16-18 Nov 2010, ppl 312-316. (Indexed-IEE/Scopus).

Arazi Idrus, K hashmi and A. M Farah. (2008). Towards Development of a Database for Civil and Structural works Production Rates. Proceedings International Conference on Construction and Building Technology, KL. 16-20 June 2008.

Arazi Idrus, Mohd Saiful Zakaria and Sana Muqeem. (2010). Development of Production Rates Database for Construction Industry by Direct Observation. Seminar and Meeting of $9^{\text {th }}$ Management in Construction Researchers's Association (MICRA2010), Universiti Teknologi MARA, Shah Alam. $1^{\text {st }}-2^{\text {nd }}$ Dec 2010.

Liou. F., and Borcherding, J.D. (1986). Work sampling can predict unit rate Productivity. Journal of. Construction. Engineering. Management, 112(1), 163-179

Oglesby, C.H. Parker, H.W., and Howell, G.A. (1989). Productivity Improvement in Construction. McGraw-Hill, New York.

Sana Muqeem, Arazi Idrus, Muhammad Saffuan and Muhammad Saqib. (2010). Development of Production Rates Database for External Works in Malaysian Construction Industry. Second International Conference on Construction in Developing Countries, Cairo, Egypt 3-5 August 2010.

Sana Muqeem, Arazi Idrus, Mohd Saiful Zakaria, Mohd Faris Khamidi. (2011). Modeling of Construction Labor Production Rates using ANN. International Conference on Environmental Science and Technology, Singapore 26-28 Feb 2011. (Indexed-IEE/Scopus).

Sweis, G.J. (2000). Impact of Conversion Technology on Productivity in Mansory Construction. PhD dissertation, Northwestern Univ., Evanston, III.

Table 1. Statistical Analysis of raw data

\begin{tabular}{|c|c|c|c|}
\hline \multirow{2}{*}{ Activity } & \multirow{2}{*}{ Unit } & \multicolumn{2}{|c|}{ Statistical Analysis } \\
\hline & & Mean & Variance \\
\hline \multicolumn{4}{|l|}{ Piling Spun Pile : Fine Grained Soil } \\
\hline a)Pile Driven & $\mathrm{m} /$ hour & 54.18 & 5.05 \\
\hline b)Average Depth & $\mathrm{m}$ & 44.60 & 0.46 \\
\hline c)Pile Cutting & point/hour & 6.67 & 0.27 \\
\hline \multicolumn{4}{|l|}{ Piling Spun Pile : Coarse Grained Soil } \\
\hline a)Pile Driven & $\mathrm{m} /$ hour & 19.17 & 3.15 \\
\hline b)Average Depth & $\mathrm{m}$ & 17.77 & 33.34 \\
\hline c)Pile Cutting & point/hour & 5.50 & 4.64 \\
\hline \multicolumn{4}{|l|}{ Piling Micro Pile } \\
\hline a)Boring & hour & 5.95 & 0.03 \\
\hline b)Clean up base & hour & 0.57 & 0.01 \\
\hline $\begin{array}{l}\text { c)Measuring, cutting \& } \quad \& \quad \text { fabricate } \\
\text { reinforcement cage }\end{array}$ & $\mathrm{m} /$ hour & 3.13 & 0.03 \\
\hline d)Install reinforcement cage & $\mathrm{m} /$ hour & 12.20 & 0.16 \\
\hline Excavation & $\mathrm{m}^{3} / \mathrm{hr}$ & 38.54 & 128.78 \\
\hline \multicolumn{4}{|l|}{ Formwork } \\
\hline a)Size measurement, cutting \& fabrication & $\mathrm{m}^{2} /$ hour & 14.93 & 0.24 \\
\hline \multicolumn{4}{|l|}{ Reinforcement } \\
\hline a)Size measurement, cutting \& fabrication & ton/hour & 0.59 & 0.003 \\
\hline \multicolumn{4}{|l|}{ Stump } \\
\hline a)Installing formwork & $\mathrm{m}^{2} /$ hour & 8.81 & 0.44 \\
\hline b)Concrete placement & $\mathrm{m}^{3} /$ hour & 5.23 & 0.19 \\
\hline c)Dismantle Formwork & $\mathrm{m}^{2} /$ hour & 16.37 & 1.92 \\
\hline
\end{tabular}


Table 2. Type of gang size subject to each activity

\begin{tabular}{|l|c|c|}
\hline \multicolumn{1}{|c|}{ Activity } & $\begin{array}{c}\text { Type of } \\
\text { Gang Size }\end{array}$ & $\begin{array}{c}\text { Number of } \\
\text { workers }\end{array}$ \\
\hline Piling Spun Pile & & \\
\hline a)Pile Driven & B & $3-4$ \\
\hline b)Average Depth & N/A & N/A \\
\hline c)Pile Cutting & A & $1-2$ \\
\hline Piling Micro Pile & & \\
\hline a)Boring & B & $3-4$ \\
\hline b)Clean up base & B & $3-4$ \\
\hline c)Measuring, cutting \& fabricate reinforcement cage & C & $5-6$ \\
\hline d)Install reinforcement cage & A & $5-6$ \\
\hline Excavation & & $1-2$ \\
\hline Formwork & D & $7-8$ \\
\hline a)Size measurement, cutting \& fabrication & & \\
\hline Reinforcement & D & $7-8$ \\
\hline a)Size measurement, cutting \& fabrication & & \\
\hline Stump & B & $3-4$ \\
\hline a)Installing formwork & B & $3-4$ \\
\hline b)Concrete placement & B & $3-4$ \\
\hline c)Dismantle Formwork & & \\
\hline
\end{tabular}

Table 3. Database of final production rates for selected substructure activities

\begin{tabular}{|l|c|c|}
\hline \multicolumn{1}{|c|}{ Activity } & Unit & Production Rate \\
\hline Piling Spun Pile : Fine Grained Soil & & \\
\hline a)Pile Driven & $\mathrm{m} / \mathrm{hour}$ & 54.18 \\
\hline b)Average Depth & $\mathrm{m}$ & 44.6 \\
\hline c)Pile Cutting & point/hour & 6.67 \\
\hline Piling Spun Pile : Coarse Grained Soil & & \\
\hline a)Pile Driven & $\mathrm{m} / \mathrm{hour}$ & 19.17 \\
\hline b)Average Depth & $\mathrm{m}$ & 17.77 \\
\hline c)Pile Cutting & point/hour & 5.5 \\
\hline Piling Micro Pile & & \\
\hline a)Boring & hour & 5.95 \\
\hline b)Clean up base & hour & 0.57 \\
\hline $\begin{array}{l}\text { c)Measuring, cutting \& fabricate } \\
\text { reinforcement cage }\end{array}$ & $\mathrm{m} / \mathrm{hour}$ & 3.13 \\
\hline d)Install reinforcement cage & $\mathrm{m} / \mathrm{hour}$ & 12.2 \\
\hline Excavation & $\mathrm{m} / \mathrm{hr}$ & 42 \\
\hline Formwork & & \\
\hline a)Size measurement, cutting \& fabrication & $\mathrm{m}^{2} / \mathrm{hour}$ & 14.93 \\
\hline Reinforcement & & \\
\hline a)Size measurement, cutting \& fabrication & ton/hour & 0.59 \\
\hline Stump & & 8.91 \\
\hline a)Installing formwork & $\mathrm{m}^{2} / \mathrm{hour}$ & 5.25 \\
\hline b)Concrete placement & $\mathrm{m} / \mathrm{hour}$ & 16.69 \\
\hline c)Dismantle Formwork & $\mathrm{m}^{2} / \mathrm{hour}$ & \\
\hline & & \\
\hline
\end{tabular}




\begin{tabular}{|c|c|c|c|c|c|}
\hline \multicolumn{6}{|c|}{ ANOVA Excavation } \\
\hline$\overline{\text { Source }}$ & SS & df & MS & $\mathbf{F}$ & P-Value \\
\hline Columns & 2515.12 & 3 & 838.375 & 37.53 & $2.08 \mathrm{e}-008$ \\
\hline Error & 446.83 & 20 & 22.342 & & \\
\hline Total & 2961.96 & 23 & & & \\
\hline \multicolumn{6}{|c|}{ ANOVA Spun pile/Micro Pile } \\
\hline Source & SS & df & MS & $\mathbf{F}$ & P-Value \\
\hline Columns & 4901.33 & 2 & 2450.67 & 626.59 & $3.5 \mathrm{e}-015$ \\
\hline Error & 58.67 & 15 & 3.91 & & \\
\hline Total & 4960 & 17 & & & \\
\hline \multicolumn{6}{|c|}{ ANOVA Reinforcement } \\
\hline Source & SS & df & MS & $\mathbf{F}$ & P-Value \\
\hline Columns & 0.01701 & 3 & 0.00567 & 2.15 & 0.1253 \\
\hline Error & 0.05265 & 20 & 0.00263 & & \\
\hline Total & 0.06966 & 23 & & & \\
\hline \multicolumn{6}{|c|}{ ANOVA Formwork } \\
\hline Source & SS & df & MS & $\mathbf{F}$ & P-Value \\
\hline Columns & 0.12458 & 3 & 0.04153 & 0.15 & 0.9265 \\
\hline Error & 5.425 & 20 & 0.27125 & & \\
\hline Total & 5.54958 & 23 & & & \\
\hline \multicolumn{6}{|c|}{ ANOVA Stump } \\
\hline Source & SS & df & MS & $\mathbf{F}$ & P-Value \\
\hline Columns & 3.7917 & 3 & 1.26389 & 4.03 & 0.0214 \\
\hline Error & 6.2667 & 20 & 0.31333 & & \\
\hline Total & 10.0583 & 23 & & & \\
\hline
\end{tabular}

Figure 1. Analysis of Variance 